\section{El manierismo en la moda. Saturación y agotamiento del gusto}

Diana Fernández ${ }^{(1)}$

Resumen: El carácter efímero de la moda constituye un elemento consustancial de su existencia. Es esa fugacidad arbitraria lo que la singulariza y marca la principal diferencia con otros comportamientos del ser humano. El manierismo como tendencia al rebuscamiento expresivo y gusto por la acentuación de determinadas características artísticas hasta que resultan afectadas, servirá de hilo conductor del presente texto, revelando su presencia en la moda como expresión del carácter autodestructivo de la moda y su reflejo en la exageración de estilos que anuncian el tránsito a uno nuevo, algo que se evidencia en varios momentos de la historia del vestir.

Palabras clave: Sistema de la moda - manierismo - gusto - estilo - consumo - tendencia historia - innovación - arte - sociedad.

[Resúmenes en inglés y portugués en las páginas 230-231]

(1) Licenciada en Teatrología por la Facultad de Artes Escénicas del Instituto Superior de Arte de La Habana, Cuba. Investigadora y docente en el campo del vestuario histórico y escénico. Profesora en diversas instituciones españolas y latinoamericanas. Autora de textos sobre su especialidad, entre ellos: Vestir al personaje. Vestuario escénico: de la historia a la ficción dramática, Ed. Cumbres, Madrid, 2018 y Lo cubano en el vestir: apuntes esenciales, Ed. Unión, La Habana, 2018.

\title{
Introducción
}

Según el Diccionario de la Lengua de la Real Academia Española, manierismo puede definirse como: "1. m. Estilo artístico y literario del Renacimiento tardío, caracterizado por su refinamiento y artificiosidad”. / “2. m. Tendencia al rebuscamiento expresivo” (RAE, 2021). Otros vocabularios lo definen también como: "Gusto por la acentuación de determinadas características artísticas hasta que resultan afectadas” (OL, 2021).

El término manierismo, acuñado como denominación historiográfica del periodo y estilo artístico del Cinquecento italiano, inicialmente fue utilizado para designar la imitación de los pintores a los grandes maestros reconocidos del arte renacentista, como expresión 
que definía a los artistas que pintaban alla maniera di, es decir, siguiendo la línea de otro creador o estilo. Posteriormente se generalizó como expresión para significar cualquier reacción contra el ideal de belleza clasicista y referirse a la alteración de las formas armónicas, involucrando aspectos como el equilibrio, la armonía, lo aceptado, como sinónimo de un estilo extravagante, afectado, degenerativo y dado a los excesos.

Estas últimas consideraciones sobre el manierismo podrían aplicarse a la moda en el vestir y relacionar este concepto con la exageración de sus formas que anuncian el tránsito a una nueva moda, algo que se evidencia en varios momentos de la historia. Sin entrar a debatir sobre aspectos relacionados con la teoría del gusto, el juicio estético, su relatividad e íntima relación con las estructuras de la subjetividad, son ideas dirigidas a destacar la relación entre el agotamiento del gusto y los estilos impuestos por la moda.

Varios filósofos y estetas han realizado estudios sobre lo bello y su proceso de desaparición después de lograr su máximo alcance a partir de la saturación de recursos lógicos-formales. Algunos estudiosos destacan que lo intersubjetivo y el relativismo del gusto es sinónimo de flujo, cambio, subversión y que, al estar inmerso en las determinaciones de lo histórico, también puede provocar la ruptura, condicionada por la independencia/dependencia intersubjetiva, propiciando que se mantenga activo, vivo y, a la vez, en permanente actitud de transformación (Fajardo, 2002).

Se ha escrito también sobre el carácter efímero de la moda, como elemento consustancial de su existencia. Teóricos como Georg Simmel, Thorstein Veblen, Jean Baudrillard, René König, Giles Lipovetsky, por solo citar algunos, han enfatizado esta compleja dimensión del fenómeno moda como premisa para efectuar sus estudios. Es esa fugacidad arbitraria lo que singulariza a la moda y marca la principal diferencia con otros comportamientos del ser humano como los hábitos, las costumbres, o el destino final de la moda: la apariencia. El filósofo alemán Simmel fue uno de los primeros en relacionar la moda a sus estudios sobre los procesos de individualización y socialización, destacando la tendencia del individuo a la imitación, como tránsito de las preocupaciones de la vida grupal a la individual. Pero más que tránsito, Simmel enfatiza que ello supone un conflicto, entre la necesidad de autoafirmación y la conformación o tendencia del ser en sociedad de apoyarse en las decisiones de ésta, librándose de lo complejo que resulta ser original o diferente. Simmel, con esta teoría, sedimenta las bases de lo que constituye la esencia de la psicosociología de la vestimenta, encontrando el vínculo exacto que, en el fenómeno moda, se relaciona con lo social e individual y dando paso a ese par categorial integrarse/destacarse, como actitud ambivalente que estará presente en todo ser humano ante el acto de vestirse (Simmel, 2014).

La visión sociológica de este pensador sobre la moda está presente en sus reflexiones al destacar que el proceso de imitación es vertical, pasando de las clases inferiores a las que se consideran superiores (Simmel, 2014). Esa verticalidad en la movilidad de la moda como única vía que propicia los cambios, traducida por la sociología moderna con la denominación de trickle-down effect, ha sido revisada por otros autores al entender que las innovaciones son producidas también entre los propios miembros de un grupo como rasgo de competitividad de distinción intergrupal, lo cual potencia, aún más, la dinámica del cambio. El sistema moda, en cualquiera de sus etapas está caracterizado por la renovación incesante de sus formas. El paso continuo de una moda a otra, su temporalidad, 
el incesante movimiento de transformación, evidencian que el sentido de obsolescencia es un elemento consustancial a esa manifestación cambiante de la indumentaria que es la moda en el vestir.

Las formas de vida efímeras propias de la moda, la sustitución de unos paradigmas de lo bello y su posterior agotamiento, constituyen el punto de partida para un análisis sobre su carácter autodestructivo, basado en la observación formal de diversos momentos de la historia del vestir.

\section{El manierismo en la moda}

La lucha constante entre la tendencia a la estabilidad y su opuesto, la inclinación continua por la novedad o lo extravagante, ha sido motivo de estudios con diversidad de enfoques, la mayoría de los cuales consideran este efecto como la propia esencia de la moda. El período de tiempo de estos cambios depende de muchos factores, no todos ellos susceptibles de ser justificados, pues la lucha por conciliar la permanencia de una moda con el ansia de su cambio ha sido el motor propio de la evolución de las formas vestimentarias a través de la historia. Por ello, en la mayoría de las ocasiones no es posible desentrañar las causas exactas de tales transformaciones.

Simmel atribuye este fenómeno de temporalidad de la moda a la mencionada contradicción entre lo general, único y unitario y lo particular, diverso y múltiple. Señala que, una vez alcanzada la generalización de una moda como culminación de su proceso de expansión, se pasa a la pérdida -gradual o impulsiva- de su condición; por tanto, la consecución en la finalidad absoluta de una moda entra en contradicción consigo misma y acaba siendo aniquilada (Simmel, 2014).

$\mathrm{Al}$ revisar ciertas etapas de la evolución de la moda es fácil advertir aquellas en las que quedan establecidas las características propias que la definen y diferencian de otras anteriores o posteriores. Pero esos esquemas o cánones de belleza ya marcados, al tiempo comienzan a alterarse y, aún sin llegar a ser sustituidos por otros diferentes, se presentan en un corto período como exageraciones de un estilo determinado que, después de haber sido aceptado, reconocido y generalizado, comienza a desvelar su desaparición. Se trata de una especie de fase de decadencia, en la que a esas rarezas que adquieren las formas, podrían ser relacionadas con la búsqueda de una nueva y diferente tendencia estética.

El sociólogo alemán König, en su análisis sobre la problemática del cambio y permanencia de la moda, destaca que para cualquier estudio de su comportamiento se deben encontrar una gran cantidad de fuerzas motoras. Define como principal característica de la moda su polifacetismo y subraya que su mecanismo no es susceptible de analizar desde una sola raíz. Destaca la dialéctica en el proceso de establecimiento de una moda, ya que en ella se oponen paradójicamente "el cambio repentino y una tendencia a la permanencia igualmente repentina, oposición que les convoca a adaptarse mutuamente" (König, 2002, p. 55) señalando que la tendencia a la permanencia no refleja una pérdida de energía de la nueva moda, sino que ejerce como función decisiva para su realización, proceso necesario para lograr imponerse. A continuación, el autor advierte que durante el período en que una 
moda llega a afianzarse, ocurren a menudo pequeños cambios de carácter experimental que pueden prosperar o fracasar. Si dichos impulsos de cambios no prosperan, quedarían como “... abortos... ocurrencias o locuras de la moda" (König, 2002, p. 57).

Esta reflexión nos sitúa en la disyuntiva de encontrar en las exageraciones antes mencionadas más que un agotamiento del gusto, la búsqueda de uno nuevo, algo que sería complejo y casi imposible de comprobar, sin adentrarse en la propia esencia del contexto que las vio nacer. Son muchos los momentos en la historia en los que se advierte lo anteriormente señalado, de los cuales se exponen a continuación cuatro, representativos de dos períodos diferenciados de la evolución de la moda en el vestir.

Como apoyo visual para la etapa analizada se utiliza el retrato pictórico, alertando que los códigos a los que estaba sometido este género de la pintura hacen que como documento no siempre refleja con objetividad la realidad. A pesar de constituir una fuente inagotable para el estudio de las formas del traje, no queda duda que la pintura por encargo limita que el artista pueda expresar con verismo lo que observa. En los retratos de las figuras de la etapa aristocrática correspondía potenciar el lujoso imaginario de la corte. La espectacularidad del conjunto vestimentario estaba en consonancia con las bases de un arte oficial, que debía reflejar, además del poder y el lujo regidos por la estricta etiqueta y ceremonial, las aspiraciones y los deseos de una élite. Con la consolidación de las sociedades burguesas, el retrato abandona las normas extremas de la corte y el simbolismo del ideal cortesano, dotando al representado de mayor naturalidad, pero aún manteniendo la capacidad de potenciar por medio de la reproducción de tejidos y decoraciones, la ubicación social del personaje retratado.

A pesar de las posibles alteraciones de la indumentaria reproducida en el retrato pictórico, dentro de la iconografía artística ha sido la pintura la que ha logrado trasladar los mayores detalles en cuanto a materia, forma, textura, y color del traje. Aún cuando las fuentes más objetivas para su estudio son las muestras originales de prendas de vestir, la variedad de referentes visuales que proporciona el retrato solamente será sustituida posteriormente por la fotografía y el audiovisual. Por tanto, son las obras de varios pintores el referente visual utilizado en el presente texto para ejemplificar las etapas de la moda seleccionadas en las que se advierten manifestaciones manieristas.

\section{La alteración de la moda femenina renacentista veneciana}

Los focos desde donde emana la moda durante el Renacimiento variaron a lo largo de los siglos XV, XVI e inicios del XVII. La llamada moda de Borgoña o del Gótico Tardío mantuvo su influencia en Centroeuropa hasta alrededor del año 1476. Paralelamente, el estilo en el vestir del primer renacimiento italiano, difundido desde Florencia, ya se había definido a lo largo del siglo XV. Por otra parte, al inicio del siguiente siglo surge otro, procedente de Venecia, ciudad con una próspera actividad manufacturera y mercantil.

La República de Venecia logró destacar por encima de los restantes núcleos políticos de la península italiana y erigirse como pieza importante del mapa europeo, interviniendo activamente en las disputas internacionales como consecuencia del poderío territorial y 
marítimo que poseía como potencia mediterránea. Además de Roma, en Venecia se fragua lo que sería el Renacimiento italiano del Cinquecento. La ciudad se afirma como uno de los centros artísticos más vibrantes e innovadores de la península, gracias a la riqueza de su emporio, uno de los más cosmopolitas de Europa. Y a pesar del declive político que sufrió a partir del siglo XVI, el extraordinario desarrollo artístico propicia que impusiera modas en el vestir durante casi 50 años.

Definida en la primera década del siglo, la variante veneciana de la moda de inicios del siglo XVI supuso el punto de partida para los elementos comunes que caracterizarían el estilo del vestir del Renacimiento. Más allá de las diferencias nacionales, aspectos como la riqueza en los tejidos, la introducción del acuchillado de pequeñas dimensiones, la aplicación de rigidez al cuerpo en las prendas superiores, se establecen como propios de la manera de vestir en Venecia y en el resto de Europa. Nuevos conceptos de belleza se abren paso paulatinamente: el talle baja, las mangas muestran la camisa o blanquette en las sisas a través de las mangas reventadas o falsas y adquieren cada vez más volumen. Los escotes se hacen cuadrados o rectos, mostrando parte del pecho y, en ocasiones, la camisa interior. La silueta, en general, pierde la verticalidad propia del estilo del cuatrocientos y se hace cada vez más voluminosa.

Estas peculiaridades pueden ser advertidas en las representaciones pictóricas de los sectores poderosos de la sociedad debido a la explosión del retrato producida en el Renacimiento. Gracias a los elementos de renovación formal inspirados en la antigüedad como la observación de la naturaleza y el dominio de la perspectiva, los detalles del traje, de las materias y su decoración posibilitan el estudio de las formas del traje de la época. Son precisamente los pintores italianos los que inician esa tendencia de describir con minuciosidad la perfección formal de la imagen de mujeres y hombres en ese intento de revalorizar la belleza física como rasgo inigualable del ser humano.

De gran armonía fueron los exponentes del vestir de las mujeres en los primeros años del siglo y así lo atestiguan los pintores de la época. En los retratos de Raffaello Sanzio, conocido como Rafael de Urbino o simplemente como Rafael, es donde se observa la definición de la moda veneciana en su etapa clásica. A pesar de la influencia florentina del creador y de su estancia mayoritariamente en Roma, su creciente fama propició que entre 1509 y 1513 recibiera numerosas peticiones de nobles para la ejecución de retratos. En el Retrato de una joven mujer (c. 1507 -1508) también conocido como La Muda, albergado en el Palacio Ducal de Urbino, el artista representa según algunos estudiosos: a Giovanna Feltria Della Rovere, la gran protectora de Rafael, viuda de Giovanni Della Rovere, fallecido en 1501. En la obra se observan las peculiaridades de la nueva moda antes señalada, con el talle ubicado casi en la cintura, rigidez en la parte superior del cuerpo cuyo escote muestra el extremo superior bordado de la camisa, que asoma también entre las mangas voluminosas atadas al vestido.

Tanto en el extremo de prenda interior asomada por el escote, como en del segmento de la misma visible en el brazo izquierdo, se observa un delicado bordado que se conoce como trabajo negro y en inglés blackwork embroidery ${ }^{1}$. La armonía en las formas, las texturas y el color es evidente en la indumentaria que cubre a la noble italiana, complementada con un peinado sencillo, a base del cabello dividido al medio cayendo liso hacia atrás y teniendo como único adorno una fina trenza a manera de diadema. 


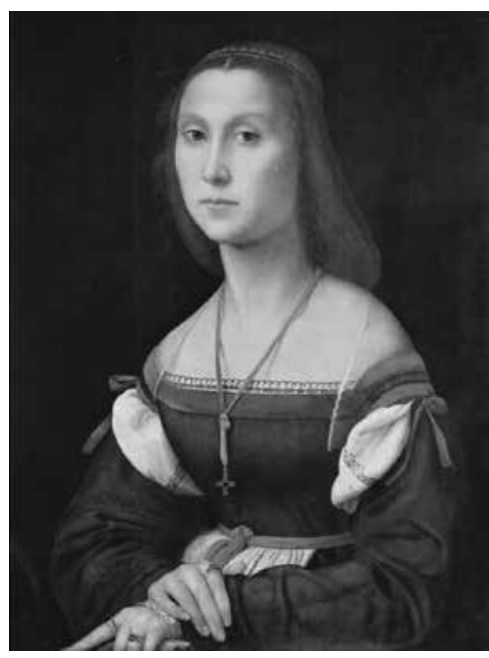

Figura 1. Rafael.

Portrait of a Woman,

La Muta. Fuente:

https://commons.

wikimedia.org/wiki/

File:Raffaello,_la_

muta.jpg

Una vez establecida, difundida y generalizada la variante veneciana de la moda renacentista italiana, las formas comienzan a exagerarse, algo que sucede a partir de la década de 1520. "El tránsito del siglo XV al siglo XVI se señaló, entre la buena sociedad y las personas que querían imitar sus maneras, por el uso de una indumentaria que resultaba tan extraña como extravagante ..." en la cual se observó un excesivo derroche en los materiales de extrema riqueza y explosión del colorido, todo parecía depender únicamente de la "ley del capricho" (Von Boehn, 1928, t. II, pp. 97-98). Aspectos como el excesivo volumen de las mangas, la manipulación decorativa de las formas con acuchillados y tejidos abullonados, los tocados exagerados, rompen con la anterior armonía y logran que el conjunto se vuelva manierista.

Esta descomposición puede observarse en una obra de Bartolomeo Veneto de 1530. El pintor, activo en Venecia desde 1502, fue contemporáneo de Tiziano, Veronés y otros maestros del Alto Renacimiento y entre sus pinturas más conocidas se encuentran los retratos. Retrato de una dama en vestido verde (1630), actualmente en el Museo de Arte Timken en San Diego, fue pintado un año antes de la muerte del artista y muestra a una dama no identificada, frente a una cortina roja, vestida con un conjunto que hace evidente el nivel de rebuscamiento alcanzado en las formas y decoración del traje. El atuendo que lleva la modelo incluye una camisola blanca ornamentada que se asoma por el puño y a través de las pequeñas y abundantes cuchilladas de las voluminosas mangas. Encima, la prenda de satén verde posee un escote cubierto con una pieza de tejido a base de un destacado trabajo negro, en este caso, con hilos rojos sobre tela amarilla. El tocado tipo rollo ${ }^{2}$, de influencia morisca, está adornado con cinta azul y dorada. Lleva un guante de halcón en su mano derecha sosteniendo el izquierdo en su mano. 


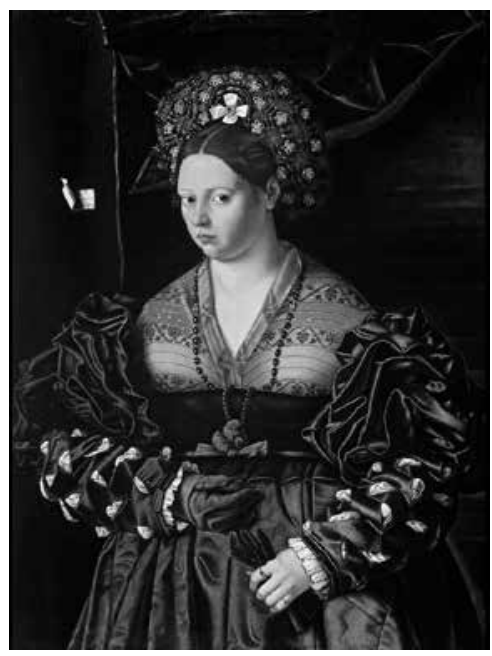

Figura 2. Bartolomeo Veneto, Portrait of a Lady in a Green Dress. Fuente: https://www. timkenmuseum.org/ collection/portraitof-a-lady-in-a-greendress/

Son varias las obras pictóricas en las que se observa este breve momento del paso de una moda a otra. Entre otras, el Retrato de una dama (c. 1510-1520) de Paolo Il Cavazzola, los retratos de damas de Bernardino Licinio o los creados por el mayor exponente de la Escuela Veneciana del Renacimiento: Tiziano, como el Retrato de Eleonora Gonzaga della Rovere, duquesa de Urbino de 1538. Todo ello como parte de la tendencia, propia de la escuela veneciana de pintura, de representar atuendos suntuosos para expresar el alto nivel de vida de los sectores poderosos de la república.

Agotamiento del gusto en la búsqueda de uno nuevo. Tiene lugar la exploración hacia nuevas formas en el vestir como reflejo de una sociedad que comienza a perder su esplendor. Los esfuerzos para detener la expansión del Imperio otomano en los Balcanes, la sesión de territorios mediterráneos como consecuencia de la guerra de 1499-1503 contra los turcos y la posterior derrota en Provenza en 1538, fueron acciones decisivas que evidenciaban el declive de la gran potencia mediterránea en los planos económico, político y militar. España y su imperio virreinal, la gran expansión comercial ultramarina de Inglaterra y Holanda, basada en las rutas del océano Atlántico, disminuyen considerablemente la influencia comercial de Venecia, reducida a un Mediterráneo menos rico, que debe entonces rivalizar con otros grandes poderes.

No dejemos de considerar también la hipótesis de Von Boehn (1928) quien se cuestiona si tales rarezas constituyen el reflejo del espíritu de la época en busca del rompimiento con una etapa precedente y como vía de potenciar el afianzamiento del individualismo en los modos y modas. Sea debido a una u otra razón, las formas del vestir de las damas venecianas dejarán de constituir el eje de atención para el resto de Europa, otras modas se abrían paso y para su legitimación debían ser asumidas y difundidas por nuevos centros de autoridad y prestigio. 


\section{La lechuguilla. La resistencia de las damas a abandonar su uso}

Después de las exageraciones del final de la moda veneciana, se produce un cambio necesario en las formas del traje. El excesivo volumen en la indumentaria de ambos sexos había llegado al máximo, el extremo rebuscamiento en las formas, colorido y texturas anunciaban la aparición de una nueva moda que estableciera un control sobre el amaneramiento general. Es el momento de España. La difusión de los usos indumentarios de la corte española en Europa fue un fenómeno cultural que tuvo su máximo desarrollo entre 1550 y 1650 como resultado del periodo hegemónico de su poder, etapa que se conoce como el gran siglo de la moda española. Luego de tres centurias en que la difusión emanaba de otros focos, España emerge como principal centro de moda. Influenciado por el ascetismo medieval y, sobre todo, en consonancia con la rectitud religiosa que querían proyectar al mundo, la corte española adoptó un estilo de gran sobriedad, caracterizado por el uso de colores oscuros, prendas ceñidas, y gran rigidez en su conjunto.

Sin lugar a dudas, los cuellos rizados constituyen un icono de la manera de vestir a la española, convertido en uno de los complementos indispensables del atuendo de mujeres y hombres. Denominado lechuguilla y generalizado su uso a partir de la segunda mitad del siglo XVI, su origen se encuentra en el pequeño borde con que se adornaba el escote de las camisas, presentes desde el estilo renacentista italiano-veneciano. Cuando la moda cortesana española impone las prendas de torso sin escote y ajustados, dicho borde adquiere más relevancia, aumenta sus dimensiones y se independiza del resto de la prenda.

Alrededor de 1570-1580 la silueta femenina propia del estilo español renacentista llega a su expresión máxima de empaque, majestuosidad y austera elegancia y así lo reproducen los pintores de la corte. Alonso Sánchez Coello, retratista de la familia real y de su entorno más cercano, realiza un alarde de maestría al detallar los ornamentos propios de las vestimentas de los nobles y cortesanos. En el retrato realizado cerca de 1584 a la infanta Catalina Micaela de Austria (1567-1597), hija de Felipe II y de la reina Isabel de Valois, que forma parte de la Colección del Museo del Prado de Madrid, se observan las formas típicas del estilo del vestir femenino renacentista español de las últimas décadas del siglo XVI. La obra muestra a la infanta de más de medio cuerpo, en pie con un conjunto negro conformado por una saya entera negra con cuello alto terminando en lechuguilla, mangas interiores en blanco y dorado, todo ello adornado con puntas de cintas blancas, collar de dos vueltas y un tocado copete, propio de la moda femenina española de la época. A pesar del exceso de rigidez, lujo y decoración, la armonía general del conjunto del atuendo es reflejada en la obra de Sánchez Coello. 


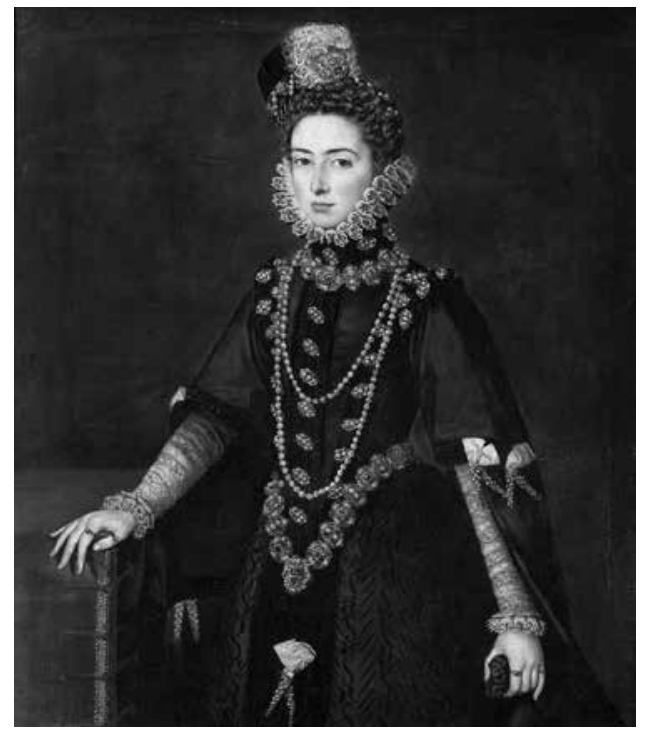

Figura 3. Sánchez Coello. La infanta Catalina Micaela de Austria. Fuente: https://www. museodelprado. es/coleccion/obrade-arte/la-infantacatalina-micaela/ bdee963c-cfb1-4f82b611-4d1120985c9b

Con la entrada del siglo XVII en la corte de España se abandona la austera elegancia de las décadas anteriores y progresivamente se advierte una alteración en la forma y el adorno. No pocos moralistas culparon de la decadencia del país a los excesos del lujo en el vestir y, entre otras manifestaciones de las exageraciones manieristas destacan las lechuguillas, las cuales adquieren dimensiones insospechadas en tiempos de Felipe III: enormes piezas de “... arquitectura artificiosa de lienzos plegados que rodea como una aureola las graves testas de los hidalgos ..." (Lozoya, 1929, t. III-VI) que fueran objeto de duras críticas por parte de quienes consideraban a sus portadores poco patriotas ya que para fabricarlas se utilizaban tejidos extranjeros y para matizarlas, polvos azules importados desde Holanda. Con los cuellos rizados o lechuguillas sucede lo que en otras ocasiones se ha advertido en la moda: cuando las formas llegan a su máxima expresión, se anuncia el cambio de estilo. Así se produce el tránsito de la moda renacentista a la barroca, la cual no se define hasta una vez pasada las primeras décadas del siglo XVII. Esa manifestación inicial de variación del gusto se concentra en los cuellos, los cuales gradualmente pierden la rigidez y caen sobre los hombros. Son los hombres quienes aceptan con rapidez este nuevo estilo, mientras que las mujeres se mantienen fieles a la moda de los cuellos rizados y rígidos, llegando a utilizarlos en enormes dimensiones.

Los retratos de la época son testigos fieles de la insistencia de las mujeres en mantener el uso de las enormes lechuguillas frente al cambio del estilo en los cuellos, al combinar de formas variadas el uso del encaje con la rigidez propia del estilo anterior. A lo largo de los primeros treinta años del siglo XVII, la mujer no renunció al uso de esta pieza, cuyo tamaño se mantuvo en aumento desde finales del siglo. La moda española había dominado 
el vestir cortesano en toda Europa durante cien años, pero la exageración, tanto de los cuellos como en otros aspectos del vestir, sobre todo femenino, comienza a evidenciar su fin, lo cual se observa en muchos de los retratos cortesanos de pintores como Pedro Pablo Rubens, Juan Pantoja de la Cruz o Frans Pourbus el Joven, de los años 1608-1610.

En el retrato de otra hija de Felipe II de España, Isabel Clara Eugenia, realizado por Rubens en 1609, se puede advertir los excesos de la moda renacentista, en su etapa de agonía. En 1598 el monarca le entrega a la infanta los Países Bajos españoles y el ducado de Borgoña como dote de su próximo matrimonio con su primo hermano, el archiduque Alberto de Austria, nieto de Carlos I de España. De tal forma, ambos quedan como soberanos de dichos territorios. El retrato, actualmente en el Museo del Prado, es parte de una obra realizada conjuntamente entre Rubens, quien a su regreso a Amberes desde Italia en 1608 es nombrado pintor de cámara de los gobernadores de Flandes y su amigo Jan Brueghel el Viejo, encargada por los archiduques Alberto e Isabel Clara Eugenia, príncipes soberanos de los Países Bajos meridionales. Rubens pintó los retratos y Brueghel incorporó el paisaje y las residencias dinásticas de Tervuren y Mariemont, subrayando así la unión de los gobernadores con sus territorios.

En la obra de Rubens se observa el inmenso cuello de blonda, del tipo que entonces se llamaba lechuguilla punteada, a juego con los puños del vestido, el peinado de alto copete, adornado con diadema de forma puntiaguda, característico de las damas cortesanas y típicamente español. Exagerada también es la forma y dimensiones de los puños, el lujo en el tejido del atuendo en negro y oro, así como las joyas colocadas sobre el cuerpo del vestido.

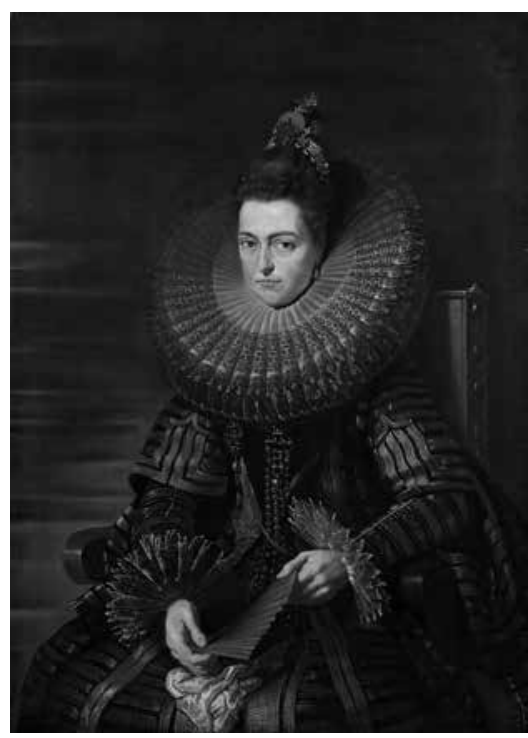

Figura 4. Rubens

Isabella Clara

Eugenia, regent of the Netherlands. Fuente: https://www. museodelprado. es/coleccion/obrade-arte/la-infantaisabel-clara-eugenia/ beff0a27-a731-47d8b48e-144f8f98de8c 
Antes de concluir el siglo XVI y durante los reinados de los últimos reyes de la Casa de Austria, la Monarquía española inició un proceso de paulatino agotamiento y desgaste. El Imperio hispánico, aquel en el que nunca se ponía el sol, como potencia hegemónica de Europa y mayor economía del mundo, antes de que se iniciara la nueva centuria comienza su período de decadencia reflejada en todos los ámbitos. El gusto por vestir a la española, adoptado por todas las cortes europeas estaba llegando a su fin. El siglo XVII vería consolidarse otros poderes y, con ello, nuevos gustos, modos y modas. Pero antes de establecerse estas novedades, ya en el vestir cortesano se advertía, como se ha apuntado anteriormente, que la saturación del gusto daba paso a elocuentes excesos en algunos aspectos del vestir, concentrados, sobre todo, en el aumento exagerado de la dimensión de los cuellos del atuendo femenino.

\section{La moda post isabelina. Del poder real a la extravagancia}

Desde finales del siglo XVI y los primeros años del seiscientos, en la mayoría de los países europeos comienzan a aparecer versiones nacionales de la moda española, como sucedió en Francia e Inglaterra. Es en la corte inglesa donde se percibe otro ejemplo de manierismo en la moda, evidente en la vestimenta femenina de la llamada era jacobea, período de la historia de Escocia e Inglaterra que coincide con el reinado de Jacobo VI de Escocia (15671625), quien también heredó la corona de Inglaterra en 1603 como James I. La era jacobea sucede a la época isabelina y precede a la era Caroline, y más allá de la política, marca un estilo propio en la arquitectura, las artes visuales, las artes decorativas, la literatura y la moda. Conviene aquí recordar el estilo del vestir cortesano precedente, impuesto por la figura y fuerte personalidad de la reina Isabel I de Inglaterra. La monarca, consciente de la importancia de su imagen como garantía de poder político, cuidó con esmero su apariencia personal. Una vez que en 1558 fuera coronada como reina de Inglaterra e Irlanda, comenzó a preocuparse por brindar una imagen que impresionara tanto a su pueblo como a otros estados extranjeros. No solamente se trataba de transmitir riqueza como habitualmente hacían todos los monarcas, sino lograr el impacto necesario a través de su apariencia que contribuye a afianzar la idea de poder. Su amor por el lujo, las joyas, los materiales suntuosos era conocido por sus leales colaboradores y ansiosos aduladores quienes no dudaban en regalarle continuamente piezas de vestimenta de gran valor. Mientras avanzaban los años de su reinado, la imagen de la Reina Virgen se hizo cada vez más recargada.

Cuando en 1603 la reina, última de la dinastía Tudor, muere sin descendencia, le sucede en el trono de Inglaterra e Irlanda, quien ya era rey de Escocia, Jacobo I, con el título de Jacobo VI. El nuevo rey, hijo de María Estuardo, gobernó conjuntamente Inglaterra, Escocia e Irlanda por espacio de 22 años hasta su muerte a los 58 años en 1625. Por tanto, la era jacobea abarca desde 1603 hasta 1625. Durante este reinado las artes decorativas se hicieron cada vez más ricas en color, detalles y diseños, influenciadas por las corrientes francesas y flamencas. Se importaron materiales de otras regiones del mundo, aumentando su utilización en la fastuosidad de los interiores de palacios y recintos cortesanos. La vestimenta no escapó a esa rebuscada tendencia. 
El estilo jacobeo de la moda femenina se aprecia claramente en los retratos, en los que se reproducen los cuellos muy elaborados, multiplicados en sus formas con la aplicación del encaje en su confección, junto al uso de materiales lujosos de gran colorido, bordados e incrustados en variedad de piedras preciosas y joyas. Todo ello marcando una silueta que no se define con un solo patrón pues algunas faldas mantienen el great farthingale, the drum, o the wheel, promovido por la última etapa de la moda isabelina, mientras otras abandonan su uso y mantienen el volumen menos destacado.

Esta moda tan recargada fue aceptada por la mayoría de las cortesanas y damas de los altos estamentos de la sociedad británica gracias a su difusión por la nueva monarca, Ana de Dinamarca (1574-1619), princesa de la Casa de Oldenburgo y reina consorte de Inglaterra y Escocia al casarse con Jacobo VI de Escocia, luego rey I de Inglaterra. La monarca pronto comprendió el poder y la magnificencia asociados a los bienes materiales y utilizó estratégicamente su apariencia física como un instrumento de la ceremonia y la diplomacia jacobeas. Su afición por las joyas y la vestimenta le valió que fuera juzgada por sus contemporáneos como extravagante, vanidosa y superficial. Como reina consorte, Ana era un símbolo de la monarquía y heredó la obligatoriedad de involucrarse en las vías de ostentación, esencialmente mediante una indumentaria suntuosa, para transmitir su riqueza, estatus y honor, lo que se traducía en poder y prestigio. Operando como códigos visuales complejos, la vestimenta de la reina en Inglaterra constituía una herramienta visual de comunicación, enfatizando la continuidad con el reinado anterior de Isabel I.

Para dejar constancia de esta riqueza de vestimenta y entorno, los pintores de la corte se multiplicaron. Se mantuvo, durante un tiempo, la figura de Marcus Gheeraerts el joven, quien era el artista favorito de Ana de Dinamarca hasta alrededor de 1617, cuando es sustituido por artistas más jóvenes como Daniel Mytens quien, aunque holandés de nacimiento, desarrolló su trabajo en la corte inglesa. Representante destacado de la escuela inglesa, William Larkin, pintor que estuvo en activo desde 1609 hasta su muerte en 1619, fue reconocido por sus retratos icónicos de los miembros de la corte de Jacobo I. El pintor londinense supo capturar en detalle la opulencia de los textiles y su manipulación en los bordados, encajes y joyas, todo ello característico de la moda en la era jacobea.

Atribuido a Larkin es el retrato de una Dama Desconocida (c. 1612), de medio cuerpo, en el cual la modelo está ataviada según el estilo post isabelino. Como primer aspecto, se percibe la presencia del encaje, género que a partir del siglo XVII se aplicaba cada vez más en cuellos, tocados o puños. Asimismo, destaca la variedad y brillantez del colorido en la combinación de tejidos y decoraciones. La dama retratada por Larkin lleva un vestido profusamente bordado con flores y fresas, enlazadas por curvas doradas que sugieren las ramas de las plantas, complementando dicha explosión de formas con un frente adornado por cintas rojas y amarillas. Encima lleva un sobrevestido sin mangas bordado con el mencionado blackwork embroidery o trabajo negro en trazos diagonales y motivos florales, festoneado con un delicado trabajo en filé dorado y adornado con pequeñas láminas de oro. El cuello de delicado encaje endurecido y apoyado en un soporte, se complementa con el tocado, necesario accesorio para cubrir el cabello, tal como lo requería el protocolo para ejercer la oración, algo que se advierte por llevar la dama, en la mano izquierda, un pequeño misal. 


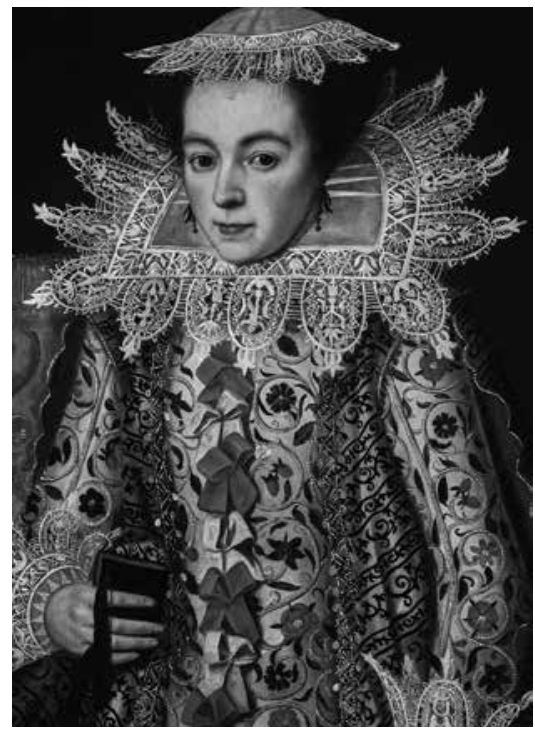

\author{
Figura 5. William \\ Larkin, Portrait of a lady \\ wearing an elaborately \\ embroidered waistcoat \\ with red and yellow \\ ribbons. Fuente: https:// \\ commons.wikimedia.org/ \\ wiki/File:William_Larkin_ \\ (attributed)_Portrait_ \\ of_a_lady_wearing_an_ \\ elaborately_embroidered_ \\ waistcoat_with_red_and_ \\ yellow_ribbons.jpg
}

Con el evidente rebuscamiento de las formas y el adorno se advierte el agotamiento del gusto de la etapa tardo-renacentista en una moda cuyo inicio y duración llegó a abarcar casi dos siglos. Poco faltaría para que se estableciera una nueva, la cual quedará definida en la década de 1630 .

\title{
De la sencillez de la moda neoclásica del Imperio a la entrada del romanticismo
}

Dos siglos después, y dentro de un nuevo orden político social, se advierten también excesos en la etapa final de la moda femenina del Imperio (1803-1815), que progresivamente se enrarece perdiendo su característica armonía y ligereza. Continuidad del conocido estilo a la antigüedad clásica o traje griego, establecido durante los años del Directorio Francés (1795-1799), la moda femenina, una vez afianzado el poder del emperador Napoleón Bonaparte, se formaliza. Sin renunciar a las líneas que caracterizan a la silueta anterior de talle bajo el pecho y falda recta se define lo que se conoce como silueta Imperio, consolidada entre los años 1803-1804.

La moda Imperio poseía un cuerpo sencillo, con un escote recto y muy bajo desde el cual salían las mangas, las más utilizadas las de tipo globo o balón, además de otras variantes. La ligereza del conjunto en los primeros años del siglo XIX ha quedado reflejada en el retrato del pintor neoclásico francés Merry-Joseph Blondel, alumno del maestro Jean-Baptiste 
Regnault y colega y amigo del pintor Ingres. En este retrato de tamaño natural el artista representa a Félicité-Louise de Durfort (1782-1872), la joven esposa del duque Pierre Riel, General de la Revolución Francesa. Posando de pie sobre una terraza en el jardín, lleva un vestido blanco que destaca la típica silueta de la moda Imperio, con un delicado adorno de cintas doradas bordeando el amplio escote y el alto talle. Un chal de cachemir color crema cuelga sobre su brazo derecho, las ligeras zapatillas forradas en raso y el peinado, acentúan la clara inspiración clásica del conjunto.

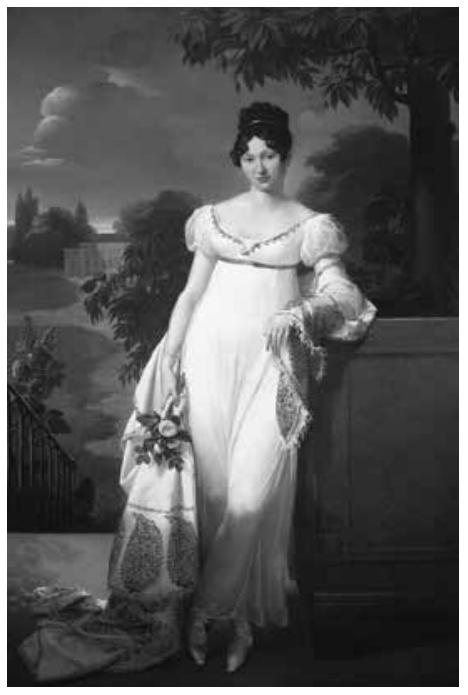

Figura 6. MerryJoseph Blondel, Retrato de FélicitéLouise de Durfort, Maréchale de Beurnonville. Fuente: https://commons. wikimedia.org/wiki/ File: Merry-Joseph_ Blondel_-_Portrait_ of_F\%C3\%A9licit\% C3\%A9-Louise_de_ Durfort,_Mar\%C3\% A9chale_de_ Beurnonville_WGA2304.jpg

De esta silueta que predominaba en los vestidos en los inicios del Imperio se pasa, año tras año, a la aparición de decoraciones más complejas en los conjuntos. Entre 1804 y 1807 se ponen de moda los adornos de influencia egipcia y etrusca, debido a los regalos traídos por el emperador Napoleón a su mujer, Josefina. Alrededor de 1808 aparecen las mangas $a$ lo mameluco, como parte de vestidos de mañana o tarde, generalmente de verano, tal como se reproducen repetidamente en los figurines de las revistas de moda de la época. Su forma era el resultado de una manga larga y amplia, dividida en secciones creadas al ajustarla al brazo, dejando que se abullona cada parte del resto y resulta similar a la manga estrangulada, muy utilizada en la moda del primer renacimiento italiano o al estilo que llevaba el conocido como vestido a la criolla o vestido camisa, propio de finales del siglo XVIII ${ }^{3}$.

Otros elementos decorativos que se introducen y contribuyen a recargar el conjunto son detalles de la moda renacentista como los acuchillados y cuellos rizados. De gran uso fue 
el conocido como escote cherrusque, cherusque o cherruse cuyo origen, según algunos autores, se atribuye a Louis Hippolyte Leroy, sastre de la emperatriz Josefina al aplicarlo a los atuendos de corte de su clienta como parte de la tendencia del creador de incorporar elementos de la indumentaria de los siglos XVI y XVII. Efectivamente el cherusque recuerda a los cuellos alzados de finales de la moda cortesana del Renacimiento y constituyó uno de los primeros elementos que brindaron una mayor decoración a las sencillas líneas de los inicios del vestir femenino durante el Imperio.

$\mathrm{Al}$ gusto por las mangas a lo mameluco y al cherusque, se añade a partir de 1811 elementos del estilo británico de la moda, influido por la corriente romántica de mirar al pasado medieval, gótico y renacentista. Este estilo, del cual los franceses hacen burlas a través de dibujos y caricaturas, se caracterizó por agregar variantes de lechuguillas o cuellos de lino rizado caídos sobre el escote, el cual se cubre en su totalidad. Detalles de tiras de tela son agregados también en las mangas, así como en el extremo de la falda, creando una imagen recargada, cada vez más alejada de la armonía del traje clásico del estilo Imperio. Como resultado, se impone una moda tan poco agraciada como extraña. Uno de sus más claros exponentes es el denominado vestido mameluco o vestido a la Gabriella, ejemplo de uno de los momentos de mayor complejidad del gusto en la imagen de la indumentaria de las mujeres. Acuchillados, cuellos rizados, piezas acolchadas aplicadas en hombros y extremos de la falda, comienzan a endurecer la inicial ligereza del conjunto. Todo ello evidencia que el gusto por lo clásico estaba en proceso de saturación y en breve se daría paso a un nuevo estilo. Así lo resume Boehm: "Las esbeltas y etéreas diosas han desaparecido y cedido su puesto a grotescas figuras que apenas tienen forma humana" (1928, p. 139).

Este momento en la evolución de la moda puede apreciarse en el retrato realizado a $\mathrm{Ma}$ dame Morel de Tangry y sus hijas, en fecha cercana a 1818 y atribuido al pintor neoclásico Louis David, como encargo durante su destierro en Bruselas desde la Restauración francesa. En este retrato de familia conservado en el Museo del Louvre de París, se representa a Rose van Tieghem y sus hijas, quienes radicaban entre Gante y Bruselas y evidencia el interés del artista de reflejar tanto la relación filial como la casta de la familia Morel, cuyo marido y padre, Anselme Louis Joseph Morel de Pangry, formaba parte del sector de grandes industriales.

En la pintura se representan a los tres personajes, ubicando en el centro de la composición a la señora, vestida de riguroso negro y como adorno más llamativo del atuendo se destaca el cuello en lino blanco inspirado en las lechuguillas renacentistas. La hija mayor lleva un vestido en seda color marfil dorado, con un profundo escote parcialmente velado por un camisolín de fino encaje que culmina con un cuello cherrusque formado por profusos pequeños volantes de lino y punta de encaje, material que poseen los puños asomados por las largas mangas del vestido. Del atuendo de la hija menor solamente se percibe parte del vestido rojo, pero se detalla el cuello, también de inspiración renacentista. Tanto la señora Tangry como su hija mayor coronan su imagen con las capotas ${ }^{4}$, ricamente decoradas con bordes de encajes, seda y flores. 


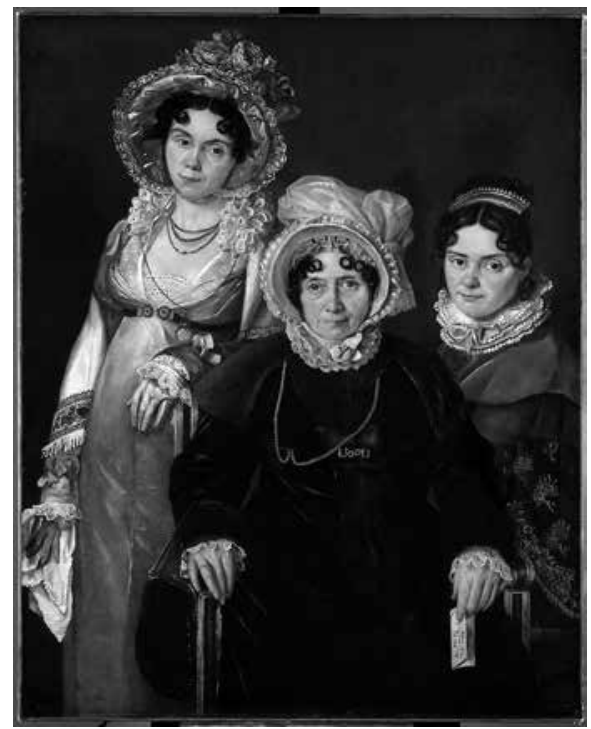

Figura 7. Louis

David (atribuido)Retrato de Madame de Tangry. Fuente: https://useum.org/ artwork/Portrait-ofMadame-De-Tangryand-Her-DaughtersJacques-LouisDavid-1816.

Aunque varios retratos reflejan este momento manierista de la historia del traje son, sobre todo, las ilustraciones de revistas de moda de la época las que reproducen con más detalle las variantes del vestir del Imperio tardío que representa una de las rarezas del final de una moda que anuncia el cambio inminente hacia otra. En esta ocasión, como reflejo de la deriva entre dos corrientes estilísticas de la historia del arte: de la racionalidad del neoclasicismo a la exuberancia del romanticismo.

\section{Final e inicio}

El final de un gusto y el inicio de otro como intermedio, proponen que, sin romper del todo con la moda precedente, se enrarezcan. Muchos más ejemplos podrían ser utilizados para sustentar este peculiar comportamiento de la moda en diversos momentos de la historia. La búsqueda incesante de novedades, el cambio constante de sus formas como elemento inherente al fenómeno moda requiere, inevitablemente, de un tránsito en el proceso de destrucción de lo viejo y el nacimiento de lo nuevo. Antes de la aparición del diseñador de moda y de la consolidación de la industria del sector, dichos cambios surgían de manera espontánea, certificados y difundidos por los grupos de mayor poder dentro de cada etapa histórica. Una vez consolidada la moda y generalizado su uso, comenzará un nuevo ciclo que se inicia con la repentina (o no) muerte de la moda precedente. 
Existen etapas en las que la sustitución de una moda por otra adquiere dimensiones de mayor calado debido a profundas transformaciones sociales: Revolución Francesa y gestación del traje burgués masculino; Primera Guerra Mundial y aparición del traje moderno femenino o Revolución Juvenil y la anti-moda de los ‘60. Pero también a lo largo de la historia, el tiempo para que se produzca el cambio ha variado según las circunstancias socioeconómicas, culturales y espirituales del momento, produciéndose el proceso de aceptación/generalización de la nueva con diferentes intervalos.

Cuando el arraigo de una moda es prolongado, para llegar a su declive se necesitan experimentos intermedios hasta que se consolide la siguiente. Es precisamente en el tránsito de esa muerte y el nacimiento de una nueva tendencia estética en el vestir, cuando se producen manifestaciones manieristas, como reflejo de la descomposición de un gusto fuertemente arraigado y el surgimiento de uno nuevo. El carácter efímero de la moda, su fugacidad y la necesidad de imponer novedades constantemente, será entonces, la fuente de su propia destrucción.

El final e inicio de una moda, la lucha constante entre la tendencia a la estabilidad y lo inevitable del cambio, el proceso de destrucción/renovación, son algunos de los aspectos que definen la esencia de la moda. El deseo de innovación del individuo como necesidad de singularización dentro de lo establecido y, sobre todo, la advertencia de la cercanía de su final es reflejada en ese manierismo en sus formas, que evidencia la saturación o agotamiento de un gusto. La moda se deja destruir, pero esto nunca significa su fin, simplemente, es la expresión de una necesaria renovación que avanzará el establecimiento de una nueva estética.

\section{Notas}

1. El blackwork embroidery, spanish blaackwork, trabajo negro, también conocido como bordado en negro, es un tipo labor realizada con hilo de seda o lana sobre lino blanco o posteriormente sobre cualquier otro tejido liso, creando un contraste cromático llamativo. Fue utilizado en la corte inglesa en el siglo XVI donde la reina Catalina de Aragón lo popularizó, por lo que se lo conoce también como bordado español, debido al origen hispano de la monarca. El hilo era generalmente negro, pero también se bordó en rojo, aplicando la técnica en puños, cuello y escote de camisas interiores.

2. Este tipo de tocado tiene su origen en el alhareme, alfareme, alfileme, utilizado por los árabes para cubrir la cabeza. Elaborado con tela, originalmente de color blanco o amarillento, las italianas lo adaptan en la segunda década del siglo XVI formando un turbante el cual posteriormente acompañan con una pieza rellena creando así el rollo.

3. No se conoce exactamente la razón por la que se identificó dicho tipo de manga con el término mameluco. Llamadas también mangas a la Gabriella, a la Juliet o a la Marie, algunos atribuyen su nombre a la presencia en algunas legiones del ejército napoleónico de los mamelucos (esclavos de origen eslavo, turco o circasianos quienes controlaban Egipto en el momento de la conquista por Napoleón en 1798). Muchos de estos guerreros formaron parte de las tropas que entraron en 1808 a Madrid, donde fueron sorprendidos por el levantamiento del 2 de mayo. Goya, años después, con su obra La carga de los mamelucos 
(1814) inmortaliza el momento de la sangrienta respuesta por parte del ejército de ocupación, formado principalmente por los mamelucos.

4. Tocado imprescindible de la moda femenina de las primeras décadas del siglo XIX; primer sombrero que cubre el cabello de la mujer cuando el furor por la moda a la antigüedad clásica se formaliza. Era elaborado de los más diversos materiales, desde fibra o tela endurecida que podía ser forrada en raso de seda, terciopelo, lana y en esta etapa se exagera su decoración con plumas, lazos, flores, hojas. El uso de la capota se prolongó hasta la década del 1860 y sus formas variaron, manteniendo la estructura básica que la caracteriza: una copa que cubre el cabello recogido en la nuca y un ala que rodea el rostro.

\section{Lista de Referencias Bibliográficas}

Avilés-Ortíz, A. (2016). Reflexiones en torno a la moda: tensiones, paradojas y frivolidades. Apuntes sobre Georg Simmel y Gabriel de Tarde. Bajo Palabra. Revista de Filosofía, II Época, No 12, pp. 265-273.

Álvarez, L. (2008). Saturación formal y efectividad estética: presupuestos en la teoría estética contemporánea. A Parte Rei. Revista de Filosofía, 55, enero 2008.

Baudrillard, J. (1998). La ilusión y la desilusión estéticas. Caracas: Monte Ávila.

Boyne, R. (2001). Subject, Society and Culture. Londres: SAGE Publications Ldt.

Diccionario de la Lengua Española. Real Academia Española. Recuperado el 11/06/2021 de: https://dle.rae.es/manierismo. Oxford Languages Dictionary. Recuperado el 13/06/2021 en https://languages.oup.com/google-dictionary-es/

Fajardo, C. (2002). El gusto estético en la sociedad postindustrial. Espéculo. Revista de estudios literarios. SSN-e 1139-3637, No. 21, 2002.

König, R. (2002). La moda en el proceso de la civilización. Valencia: Engloba edición.

Lipovetsky, G. (1990). El imperio de lo efímero. La moda y su destino en las sociedades modernas. Barcelona: Editorial Anagrama.

Lozano, J. (2000). Simmel: El atractivo formal del límite. Revista Española de Investigaciones Sociológicas. Reis 89/00, pp. 237-250.

Lozoya, marqués de (1929). Estudio Preliminar. La Moda. Historia del traje en Europa desde los orígenes hasta nuestros días. Barcelona: Salvat Editores.

Simmel, G. (2014). Filosofía de la Moda. Madrid: Editorial Casimiro Libros.

Von Boehn, M. (1928). La Moda. Historia del traje en Europa desde los orígenes hasta nuestros días, Barcelona: Salvat Editores.

Wladyslaw, W. (2004). Historia de la estética III: La estética moderna, 1400-1700. Madrid: Ed. Akal, S.L.

Abstract: The ephemeral nature of fashion is an inherent element of its existence. It is this arbitrary transience that distinguishes it and makes the main difference with other behav- 
iors of the human being. Mannerism as a tendency to expressive refinement and a taste for the accentuation of certain artistic characteristics until they are affected, will serve as the common thread of this article, revealing its presence in fashion as an expression of the self-destructive character of fashion and its reflection in the exaggeration of styles that announce the transition to a new one, something that is evident in various moments in the history of clothing.

Keywords: Fashion system - mannerism - taste - style - consumption - trend - history innovation - art - society.

Resumo: A natureza efêmera da moda é um elemento inerente à sua existência. É essa transitoriedade arbitrária que o distingue e faz a principal diferença com outros comportamentos do ser humano. O maneirismo como tendência ao refinamento expressivo e gosto pela acentuação de certas características artísticas até serem afetadas, servirá de fio condutor deste texto, revelando sua presença na moda como expressão do caráter autodestrutivo da moda e de seus reflexão no exagero de estilos que anunciam a transição para um novo, algo que se evidencia em vários momentos da história do vestuário.

Palavras chave: Sistema de moda - maneirismo - gosto - estilo - consumo - tendência história - inovação - arte - sociedade.

[Las traducciones de los abstracts fueron supervisadas por el autor de cada artículo] 